\title{
ANÁLISE DO PROJETO PARQUE LINEAR DO CÓRREGO DO BISPO
}

\author{
Isménia Andrade ${ }^{1}$ e Natacha Ferreira ${ }^{2}$ \\ 1 Arquiteta Paisagista pela Faculdade de Ciências da Universidade do Porto, Portugal - \\ E-mail: ismenia_andrade@hotmail.com \\ 2 Arquiteta Urbanista pela Universidade Nove de Julho, São Paulo - \\ E-mail: arq.natashaferreira@gmail.com
}

\begin{abstract}
Resumo
Os problemas ambientais com que a humanidade do século XXI se depara são flagrantes e com consequências irreversíveis e catastróficas. As mudanças climatéricas, em particular o aquecimento global, provocam alterações no ciclo das chuvas com o consequente aumento de enchentes responsáveis por diversas calamidades ambientais e humanas. O Programa Parques Lineares surge como uma resposta possível à proteção das áreas de várzea de diversos córregos do município de São Paulo nomeadamente, do Córrego do Bispo. Estas áreas são responsáveis por uma importante parte da drenagem urbana, podendo ser convertidas em agradáveis espaços de lazer para a população. A sua transformação em parques lineares favorece a população local, ao melhorar os níveis de salubridade ambiental e de qualidade de vida. O Parque Linear do Córrego do Bispo, situado na zona norte de São Paulo, Subprefeitura da Freguesia Casa Verde/Cachoeirinha, encontra-se em fase de licitação, aguardandose o início das obras de execução do projeto. Este córrego apresenta características únicas associadas à contiguidade da sua margem direita à Serra da Cantareira. Este trabalho tem como objetivo apresentar o Programa de Parques Lineares no Córrego do Bispo, detetar dificuldades pertinentes à execução da obra e evidenciar mais-valias ambientais e sociais à sua criação.
\end{abstract}

Palavras chave: Parque Linear, Córrego do Bispo, Desenvolvimento Urbano Sustentáveis 


\title{
ANALYSIS OF THE BISPO CREEK LINEAR PARK PROJECT
}

\begin{abstract}
The environmental problems that the XXI century humanity faces are flagrant and have irreversible and catastrophic consequences. The climate changes, specifically the global warming, causes changes in the rain cycles and increase floods, which have been responsible for many environmental and human disasters. The Linear Parks Program emerges as a possible answer to the protection of floodplain areas of different streams of São Paulo in particular, of the stream of Bispo. These areas are responsible for an important part of urban drainage and can be converted into pleasant recreational space for the population. Its transformation into linear parks encourages local people to improve levels of environmental health and quality of life. The Linear Park of the stream of Bispo, located in the north of São Paulo's Subprefecture Casa Verde / Cachoeirinha, is in the bidding stage, pending the start of work. This stream has unique characteristics associated with the contiguity of its right edge of the Serra da Cantareira. This paper aims to present the program of Linear Parks in the stream of Bispo Creek, sensing difficulties pertaining to the works and show environmental and social barriers to its creation.
\end{abstract}

Keywords: Linear Park, Stream of Bispo, Sustainable urban development

\section{METODOLOGIA}

O desenvolvimento deste estudo foi realizado com base em pesquisas bibliográficas, reportagens fotográficas no local e recolha de informação privilegiada junto dos vigilantes do parque. 


\section{INTRODUÇÃO}

A cidade de São Paulo possui cerca de 300 córregos cuja principal função está limitada ao transporte de esgotos domésticos e industriais. $O$ crescimento exponencial da população e a falta de ações de sensibilização por parte das entidades responsáveis para as questões ambientais, concorrem para que os córregos da cidade se transformem em verdadeiras lixeiras a céu aberto, com a consequente diminuição de qualidade de vida e gravidade dos riscos para a saúde pública.

A alteração no uso e ocupação do solo provocada pela urbanização - como retirada da vegetação e a impermeabilização do solo - impactam diretamente no ciclo hidrológico, em especial nos processos naturais de infiltração, armazenagem nos corpos d'água e fluxo fluvial. Por consequência, temos as alterações climáticas ocasionadas pelos impactos no meio que, dentre outras coisas, causam problemas de enchentes. Temos ainda, que a falta de saneamento é responsável por uma série de moléstias nas cidades, como leptospirose, cólera e a dengue, ou seja, a água além de fundamental para manutenção da vida no meio urbano este diretamente relacionada com a qualidade de vida (BRAGA;CARVALHO, 2003). Esta situação agrava-se com a falta de educação dos moradores das cidades que descartam lixo nas vias públicas, de pessoas que em busca de materiais recicláveis abrem sacos de lixo e espalham nas ruas o material indesejado, da falta de locais apropriados para descarte de materiais resultantes de reformas na construção civil e de outras ações impróprias que não condizem com as melhores formas de convívio urbano (SANCHES, 2006).

O programa Parques Lineares surge com resposta a estes problemas, tendo como principais objetivos a criação de um plano de adaptação ao novo cenário climático e a criação de um banco de terras públicas prestadoras de serviços ambientais.

\section{PROGRAMA PARQUES LINEARES}

O Programa Parques Lineares é implantado pela Secretaria Municipal do Verde e do Meio Ambiente da Prefeitura do município de São Paulo em Janeiro de 2008 e visa recuperar áreas de várzea da cidade através do aumento da permeabilidade do solo e diminuição de enchentes. Formulado no Plano Diretor Estratégico, considera a rede hídrica como um elemento estruturador urbano e promove a expansão das áreas verdes adjacentes. 


\section{Revista LABVERDE}

O programa identifica várias áreas de intervenção prioritária, considerando que ao serem viabilizadas enquanto parques lineares reduzirão as enchentes, sendo elas:

$\diamond \quad$ Cabeceiras do ribeirão Perús;

$\diamond \quad$ Borda da Cantareira - Cabeceiras do Cabuçú de Baixo e Cima;

$\diamond \quad$ Nascentes do Aricanduva;

$\diamond \quad$ Ribeirão Pirajussara;

$\diamond \quad$ Morro do S;

$\diamond \quad$ Cocaia e Caulim na área de mananciais.

A intenção é preservar as águas através de regularização e reurbanização de bairros precariamente instalados; urbanização de favelas; saneamento básico; congelamento de novas ocupações através da fiscalização permanente; criação de unidades de conservação; promoção de atividades esportivas e de educação ambiental; divulgação das ações junto à população.

Neste sentido, a SVMA decide comprar $3.000 .000 \mathrm{~m}^{2}$ de glebas rurais passíveis de viabilizar a implementação dos parques lineares desta região: Bananal, Canivetes, Itaguaçú e Bispo.

A realização do programa dos parques assenta em consultas públicas e em parcerias público-privadas, tendo como suporte mecanismos institucionais e legais que as prevêem explicitamente:

$\diamond \quad$ Parcerias associadas aos Termos de Compensação Ambiental - empreendedores cujos projetos necessitem do abate/extração de árvores devem indenizar administrativamente o município através de replantio ou implantação de parques, podendo ainda haver compensação monetária para financiar projetos ou obras de recuperação e requalificação de áreas verdes; 
Parcerias associadas à compra de potencial construtivo - empreendedores que desejem construir utilizando coeficiente de aproveitamento maior do que o mínimo legal, devem depositar junto ao Fundurb (Fundo de Desenvolvimento Urbano) quantia em dinheiro calculada conforme legislação. Esse fundo financia também a construção de parques, através do fomento do Programa Parques Lineares;

Parcerias associadas à venda de créditos de carbono em leilão - município e empresa privada repartem entre si os recursos decorrentes da exploração de gás em dois aterros sanitários municipais. Os recursos do município são depositados no FEMA (Fundo Especial do Meio Ambiente e Desenvolvimento Sustentável), que com esse dinheiro financiam a recuperação ambiental nas redondezas do aterro sanitário;

$\diamond \quad$ Cooperação entre a empresa de saneamento do Estado de São Paulo, que desenvolve em parceria com a Prefeitura o projeto Córrego Limpo, que trata de eliminar lançamentos de esgotos em 44 córregos.

\section{Córrego do Bispo - Subprefeitura Casa Verde/Cachoeirinha}

A Bacia Hidrográfica de Cabuçú de Baixo localiza-se na zona norte do município de São Paulo. É formada por vários córregos afluentes entre os quais o córrego do Bispo e integre uma importante área da Serra da Cantareira, um dos mais importantes remanescentes de Mata Atlântica do município e considerado pela UNESCO como reserva da biosfera.

A bacia abrange $30 \%$ do território, promovendo a drenagem de áreas cuja principal característica é a ocupação informal, desordenada e acelerada, com vastas áreas florestadas é o caso dos bairros de Vila Brasilândia, Parada de Taipas e Vila Nova Cachoeirinha, entre outros.

A bacia é constituída por relevo de morros e montanhas com grandes declividades na sua porção norte, que vai suavizando até alcançar na sua porção final a planície aluvial do Rio Tietê. A região de relevo mais acidentado, antiga zona rural, é justamente aquela com ocupação mais recente, caracterizada por invasões e ocupações 
desordenadas que provocam intenso desmatamento em áreas de risco geológico. $\mathrm{Na}$ bacia existem aproximadamente 150 favelas, sendo 28 localizadas em áreas críticas de risco geotécnico, todas na porção norte da bacia (TAKIYA, 2002).

As encostas da Serra da cantareira apresentam características litológicas que the conferem instabilidade desfavorável à ocupação, devido ao movimento de massas principalmente nos meses de verão com ocorrência de fortes chuvas. A ocupação clandestina, sem apoio técnico, de baixa renda, resultado da exclusão territorial que caracteriza a margem esquerda do córrego do Bispo torna imprescindível a realização deste parque linear, não só por questões de segurança mas também por toda a meIhoria e benefícios que a sua execução trás.

O relevo que carateriza esta região é muito acentuado/acidentado, incluindo morros e montanha, com uma altitude que atinge os $1200 \mathrm{~m}$ nas regiões mais montanhosas e 750 a $800 \mathrm{~m}$ em pequenas colinas ou em áreas fluviais.

O Córrego do Bispo (direção leste-oeste) não se encontra canalizado, tendo a sua margem direita inserida na Serra da Cantareira e a sua margem esquerda dominada por várias favelas. Tem aproximadamente $4 \mathrm{~km}$ de comprimento e é responsável pelo depósito de dejetos e sedimentos sólidos em córregos de maior dimensão, córrego Cabuçu e Tietê. 


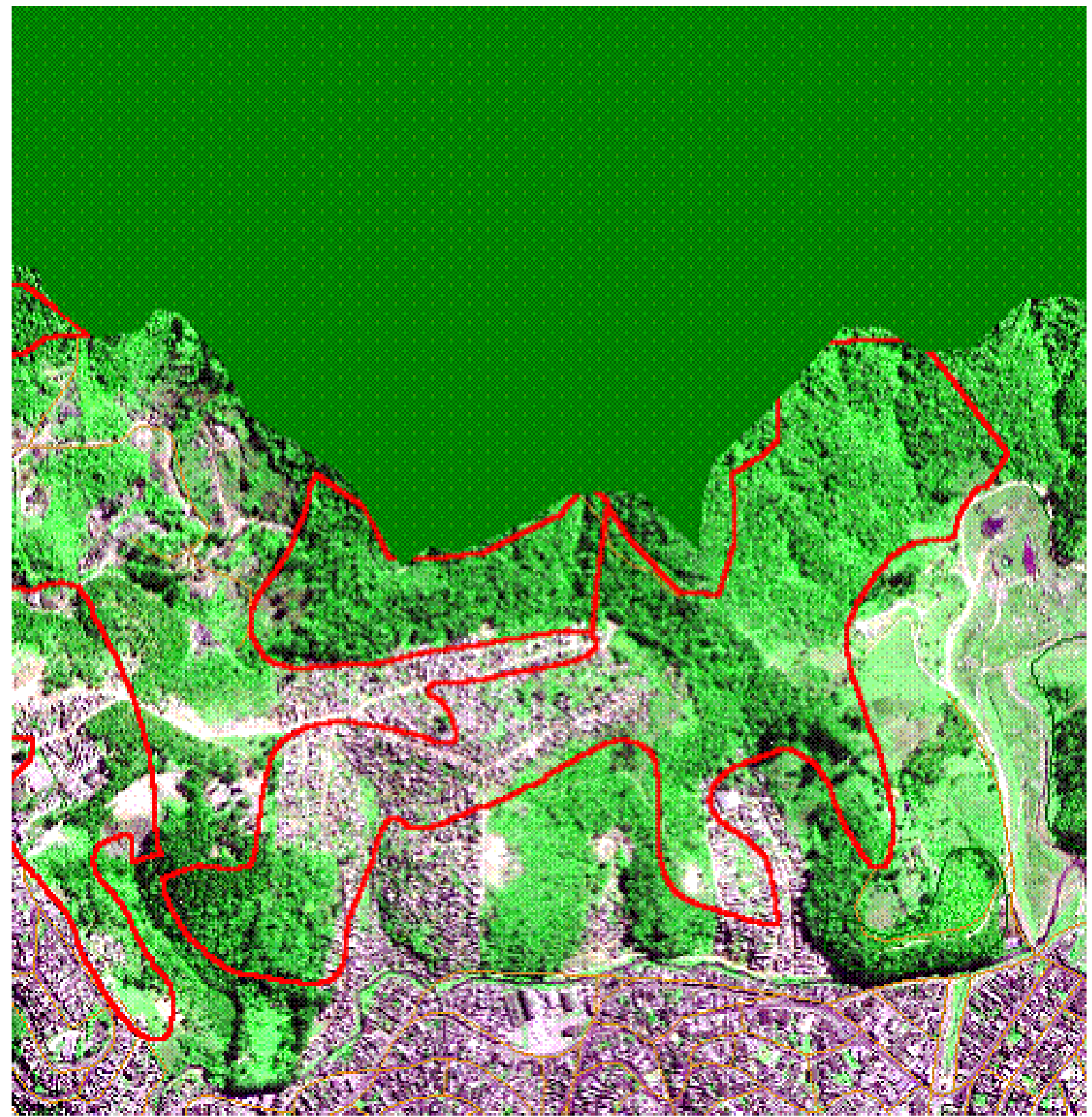

Figura 1: Bacia do Córrego Cabuçu. Em vermelho estão delimitados polígonos onde houve supressão de Vegetação Significativa (TAKIYA, 2002).

A vegetação de áreas localizadas a 300 metros do limite do Parque Estadual da Cantareira, na maior parte dos casos é preservada. Os polígonos localizados no entorno desta área permaneceram, embora muitos com redução significativa na sua extensão. As unidades de vegetação significativa que deixaram de existir correspondem aos maiores polígonos, distantes do entorno Parque Estadual da Cantareira, localizados em áreas densamente ocupadas ou em processo de ocupação (TAKIYA, 2002). 
Tendo como base a classificação de áreas públicas existentes na base cartográfica digital GEOLOG (na escala 1:10.000) do Município de São Paulo, é possível verificar que na Bacia do Cabuçu de Baixo quase não restam mais áreas públicas livres. Por isso o processo de ocupação nos últimos anos passou de um modelo de invasões em áreas públicas para a ocupação irregular de terrenos particulares, com ou sem consentimento dos proprietários, configurando-se em um modelo de ocupação por loteamentos clandestinos de baixo padrão (TAKIYA, 2002).

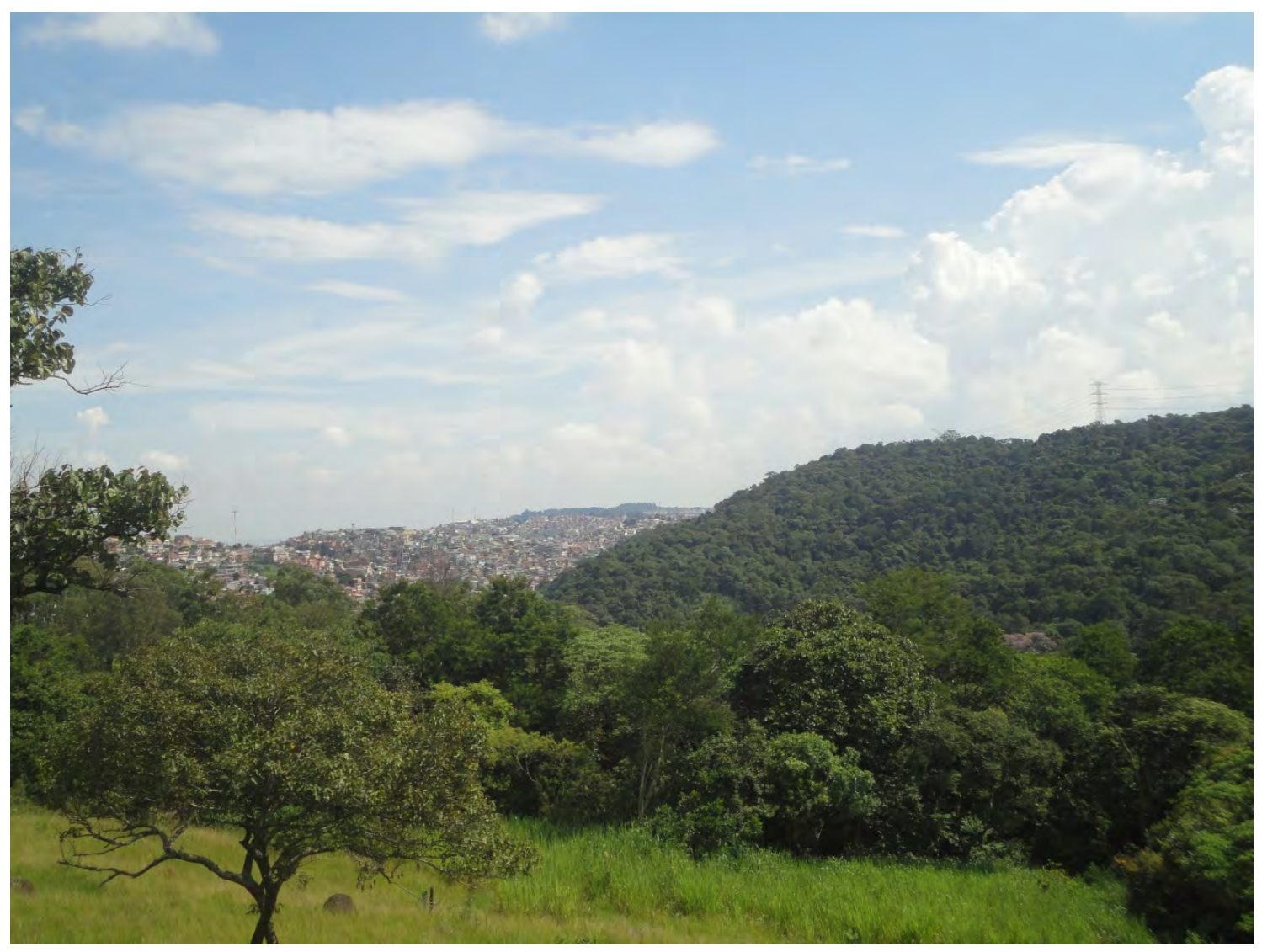

Figura 2: Vista sobre a Serra da Cantareira em contraste com a construção clandestina existente nas suas imediações. Fonte: Imagem das autoras Isménia Andrade e Natacha Ferreira.

O clima predominante na região é classificado como mesotérmico e úmido com verão chuvoso e inverno seco (Cwa de Koeppen), em que os meses com temperaturas médias mais elevadas são janeiro e fevereiro, com $23^{\circ} \mathrm{C}$ e $22,8^{\circ} \mathrm{C}$, respetivamente, e os meses com temperaturas mais reduzidas são junho e julho, com $16,6^{\circ} \mathrm{C}$ e $16,5^{\circ} \mathrm{C}$, respetivamente. 
O período chuvoso estende-se de outubro a março, sendo o período seco entre os meses de abril a setembro. A precipitação média anual é de $1.322 \mathrm{~mm}$ por ano (série 1992-2007), sendo que o mês mais chuvoso é Janeiro (229,8 mm) e o mês mais seco Agosto $(31,7 \mathrm{~mm})$.

\section{Plano Regional Estratégico da Subprefeitura Casa Verde/Cachoeirinha}

De acordo com o Plano Regional Estratégico da Subprefeitura Casa Verde - PRE CV, Livro IV - Anexo à Lei n 13.885, de 25 de agosto de 2004, Capítulo IV - Dos Objetivos para o Desenvolvimento Urbano com Qualidade Ambiental, é considerado relevante para a execução do Parque Linear do Córrego do Bispo os seguintes aspectos:

Art. $4^{\circ}$ - São objetivos do desenvolvimento urbano com qualidade ambiental:

VII. completar a Avenida Afonso Lopes Vieira, traçando seu prolongamento de forma ascendente, preservando as margens do Córrego Guaraú até a Avenida Peri Ronchetti, como via estrutural N3, situada ao norte da Subprefeitura Casa Verde/Cachoeirinha, localidade carente de ligações perimetrais, visando à preservação da Serra da Cantareira;

VIII. restringir obras viárias junto à Serra da Cantareira, de forma a impedir a ocupação de suas encostas.

Título II - Do Plano Urbanístico-Ambiental

Art. $5^{\circ}$ - Este Plano Regional Estratégico, observado o disposto no Capítulo I do Título III da Lei 13.430, de 13 de setembro de 2.002 - Plano Diretor Estratégico (PDE), estabelece diretrizes para os elementos estruturadores e integradores como parte do processo de urbanização da subprefeitura.

Capítulo I - Dos Elementos Estruturadores

Seção I - Rede Estrutural Hídrica Ambiental

Art. $6^{\circ}$ - A Rede Estrutural Hídrica Ambiental de Casa Verde/Cachoeirinha compreende as bacias do Córrego do Bispo e Córrego 
Guaraú, áreas verdes e áreas degradadas constantes do Quadro 01 e Mapa 01, integrantes deste Livro, compreendendo:

I. parque linear do Córrego do Bispo localizado ao sul da Serra da Cantareira, no Distrito de Cachoeirinha, para o qual são definidas as seguintes diretrizes:

a) melhorar as condições do entorno do Córrego do Bispo e dos recursos hídricos da região norte;

b) reassentar a população residente em suas margens para local mais apropriado ao uso habitacional;

c) implantar viveiro municipal na faixa de 15 metros "non aedificandi" de cada um das margens do córrego, visando atender ao programa de arborização da Macrozona de Reestruturação e Qualificação Urbana da Subprefeitura Casa Verde/Cachoeirinha;

d) criar uma barreira de proteção da Serra da Cantareira, dificultando ocupações clandestinas;

e) promover a reurbanização de área contígua ao parque linear do Córrego do Bispo delimitada como ZEIS 1, até 2006, visando à relocação da população moradora nas margens do córrego;

f) promover programa de educação ambiental para garantir os usos e a ocupação desejada;

g) implantar, até 2012, o plano da Área de Intervenção Urbana, atendendo as normas específicas da Zona Mista de Proteção Ambiental, que prevê usos residenciais, atividades comerciais, de prestação de serviços e indústrias não incômodas de baixa densidade.

Título III - Do Uso e Ocupação do Solo

Capítulo I - Das Macrozonas

Art. 14 - Segundo o Quadro 17 e Mapa 05 do PDE, a Subprefeitura de Casa Verde/Cachoeirinha encontra-se, em parte, contida na Macrozona de Estruturação e Qualificação Urbana e, em parte, na Macrozona de Proteção Ambiental.

Seção I - Macrozona de Proteção Ambiental 
Art. 15 - Fica sujeita às disposições do artigo 150 do PDE parte do território do Distrito de Cachoeirinha, entre as divisas com os Distritos de Brasilândia e Mandaqui.

Subseção I - Macroárea de Proteção Integral

Art. 16 - Está contida na Macroárea de Proteção Integral, conforme dispõe o artigo 151 do PDE, a ZEP - Zona Especial de Preservação, que compreende parte do Parque Estadual da Serra da Cantareira, localizado no Distrito de Cachoeirinha.

Subseção II - Macroárea de Conservação e Recuperação

Art. 17 - Estão contidas na Macroárea de Conservação e Recuperação, conforme dispõe o artigo 153 do PDE, compreendendo parte do Distrito de Cachoeirinha:

I. ZEPAM - Zona Especial de Preservação Ambiental;

II. ZMp - Zona Mista de Proteção Ambiental.

Art. 18 - Fica instituída Área de Proteção Ambiental - APA do Córrego do Bispo, contígua à ZEP- 01 - Reserva Cantareira, sujeita às disposições do artigo 153 do PDE, enquadrada na Macroárea de Conservação e Recuperação.

Capítulo II - Das Zonas de Uso

Seção V - Das Zonas Especiais

Subseção I - Das Zonas Especiais de Preservação Ambiental - ZEPAM

Art. 28 - Ficam enquadradas nas Zonas Especiais de Preservação Ambiental - ZEPAM, conforme dispõe o artigo 167-A do PDE, as seguintes áreas:

I. ZEPAM/01 - Córrego do Bispo da Serra da Cantareira, para a qual são estabelecidas as seguintes diretrizes:

a) Manter as características da paisagem natural, através de normas específicas que direcionem a ocupação destas áreas para usos 
sustentáveis, compatíveis com a sua preservação e manutenção da baixa densidade construtiva e da baixa taxa de ocupação;

b) Transformar parte da ZEPAM em APA - Área de Proteção Ambiental, constituindo-se em barreira de proteção da Serra da Cantareira;

Capítulo III - Dos Instrumentos de Gestão Urbana Ambiental

Art. 31 - As diretrizes para aplicação dos Instrumentos de Gestão Urbana e Ambiental - parcelamento, edificação ou utilização compulsória, direito de preempção, outorga onerosa do direito de construir e transferência do direito de construir, previstos no PDE, e a delimitação das áreas para esta aplicação estão especificadas, conforme o caso, neste PRE.

Seção I - Da Transferência do Direito de Construir

Art. 32 - Os proprietários dos imóveis situados na faixa delimitada para a implantação do parque linear do Córrego do Bispo poderão transferir o potencial construtivo conforme as disposições dos artigos 217 a 220 do PDE e nas disposições desta Lei.

Art. 34 - A AIU Parque Linear do córrego do Bispo está contida na ZMp - Zona Mista de Proteção, conforme características do Quadro 04 e delimitadas no Mapa 04, integrantes deste Livro. 
Plano Regional Estratégico da Subprefeitura Casa Verde - PRE - CV

Quadro 01 do Livro IV - Anexo à Lei n 13.885, de 25 de agosto de 2004.

Rede Estrutural Hídrica Ambiental

\begin{tabular}{|c|c|c|c|c|}
\hline $\begin{array}{l}\text { Parque } \\
\text { Linear }\end{array}$ & Perímetro & Distrito & $\begin{array}{c}\text { Quantificação } \\
\left(\mathrm{m}^{2}\right)\end{array}$ & Horizonte \\
\hline $\begin{array}{l}\text { Córrego } \\
\text { do Bispo }\end{array}$ & $\begin{array}{l}\text { Área 1: Começa na confluência } \\
\text { da Av. Inajar de Souza com a R. } \\
\text { Gervásio Leite Rebelo. Segue } \\
\text { pela Gervásio Leite Rebelo, R. } \\
\text { Taquaraçu de Minas, R. São Ro- } \\
\text { que de Minas, R. São Miguel do } \\
\text { Tapuio, R. São Roque de Minas, } \\
\text { Av. Francisco Machado de Minas, } \\
\text { Estrada da Sede, R. s/n, limite da } \\
\text { Zona Non Aedificandi contornan- } \\
\text { do o Córrego do Bispo (15 me- } \\
\text { tros das margens), e Av. Inajar de } \\
\text { Souza até o ponto inicial. } \\
\text { Área 2: Começa na confluência } \\
\text { da R. Palmas de São Moisés, } \\
\text { com a Av. Francisco Machado } \\
\text { da Silva. Segue pela Av. Fran- } \\
\text { cisco Machado da Silva, R. s/n, } \\
\text { Av. Santa Inês, limite da Zona } \\
\text { Non Aedificandi contornando o } \\
\text { Córrego (15 metros das mar- } \\
\text { gens), segmento 1-2-3 que liga } \\
\text { o limite da Zona Non Aedificandi } \\
\text { com o fim da R. Palmas de São } \\
\text { Moisés, fechando o perímetro } \\
\text { no ponto inicial. }\end{array}$ & $\begin{array}{l}\text { Cacho- } \\
\text { eirinha }\end{array}$ & 386.547 & 2012 \\
\hline
\end{tabular}

Fonte Retirada: Plano Regional Estratégico da Subprefeitura Casa Verde - PRE - CV Quadro 01 do Livro IV - Anexo à Lei no 13.885, de 25 de agosto de 2004.

Rede Estrutural Hídrica Ambiental 


\section{Situação atual do projeto Parque Linear Córrego do Bispo}

O Parque linear do Córrego do Bispo encontra-se em fase de licitação, tendo sido realizado até à data o cercamento do local com alambrados e muro de arrimo em uma extensão de mil metros e a construção de três guaritas de segurança, com permanência constante de guardas, para possibilitar o controlo da construção de habitações clandestinas.

Está prevista para a região a construção do Trecho Norte do Rodoanel - de responsabilidade da Desenvolvimento Rodoviário S.A. (Dersa), empresa ligada ao governo do Estado. No Parque Linear do Córrego do Bispo, a Prefeitura pretende que seja feito um túnel ao longo do terreno, argumentando que o viaduto previsto causará grande impacto e descaracterização do vale da "Fazendinha", com a consequente eliminação de vegetação e com o aumento do ruído provocado pelos veículos, causando desconforto aos utilizadores do futuro parque.

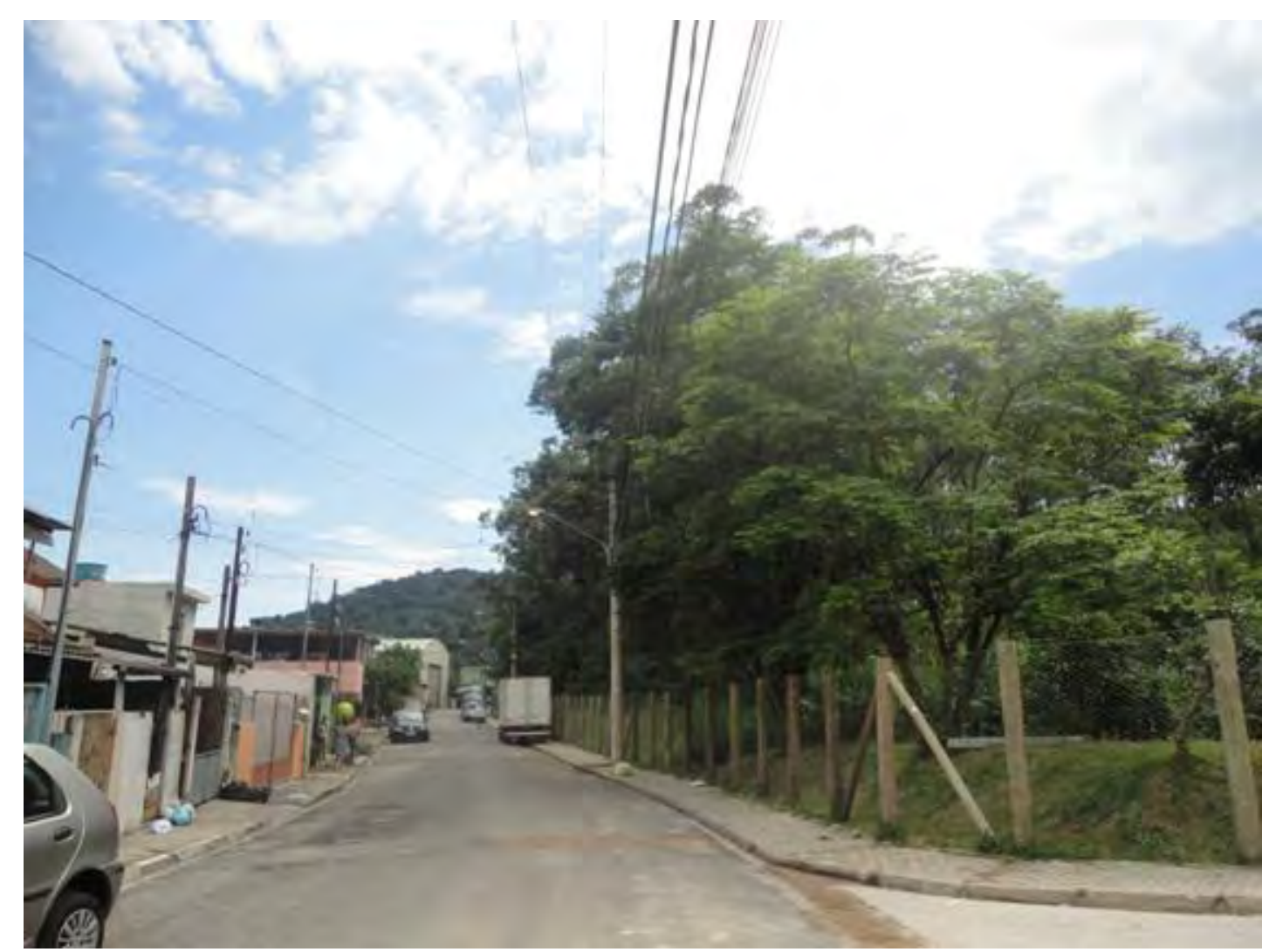

Figura 3: Vedação existente na área prevista para o Parque Linear. Fonte: Imagem das autoras Isménia Andrade e Natacha Ferreira. 


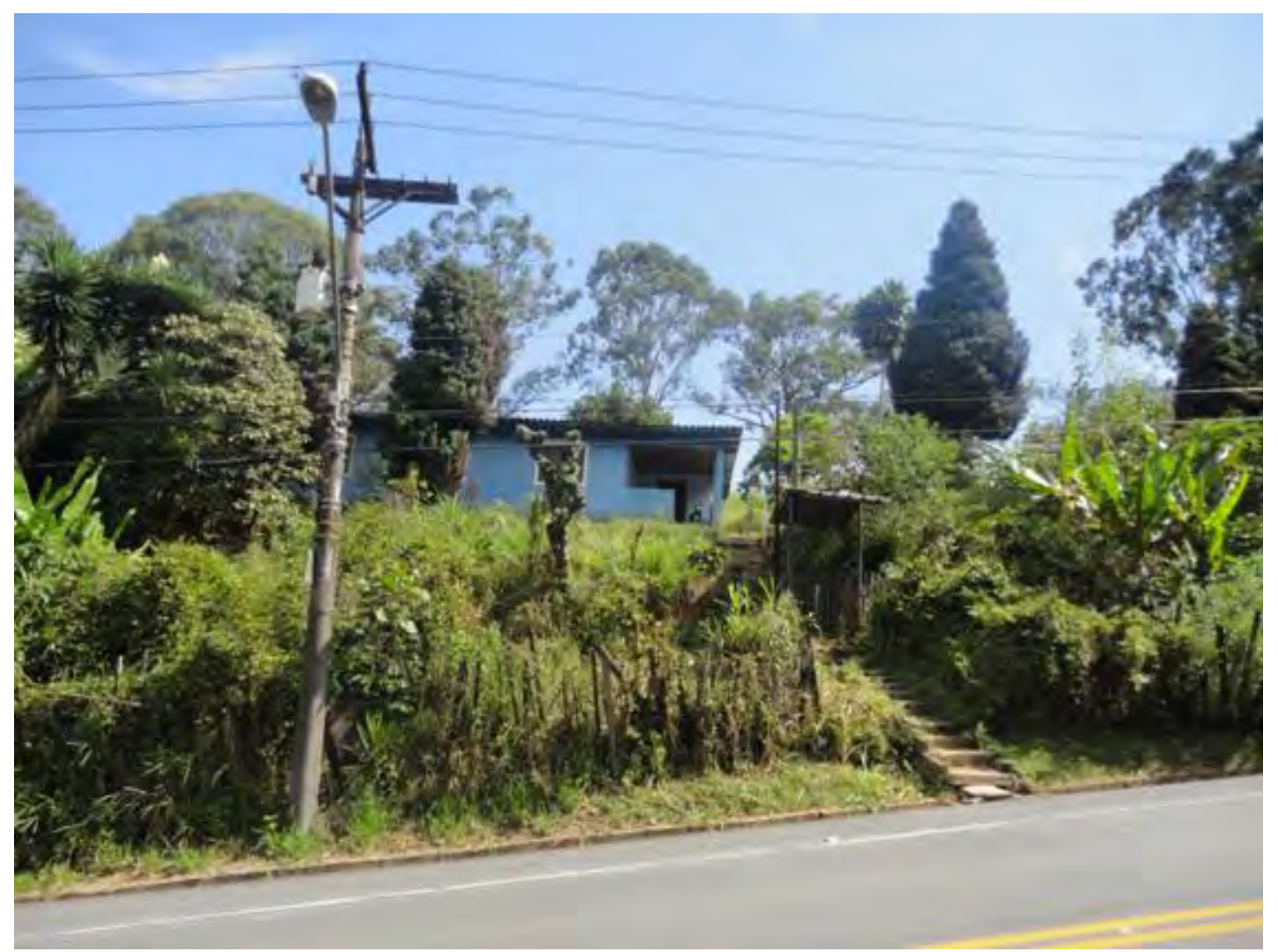

Figura 4: Guarita existente na área prevista para o Parque Linear. Fonte: Imagem das autoras Isménia Andrade e Natacha Ferreira.

\section{CONCLUSÃO}

Várias são as consequências positivas inerente à realização do Parque Linear do Córrego do Bispo, destacando-se as seguintes funções:

$\diamond \quad$ Função de drenagem e de melhoria da rede hídrica: tratando-se de uma região de declive acentuado e sinuoso, onde a vegetação ciliar foi em parte eliminada e substituída por habitação precária, com entorno impermeabilizado em áreas consideráveis, a construção deste parque assegura a drenagem e a melhoria do sistema hídrico local, diminui os riscos de contato com esgotos e águas contaminadas. 


\section{Revista LABVERDE}

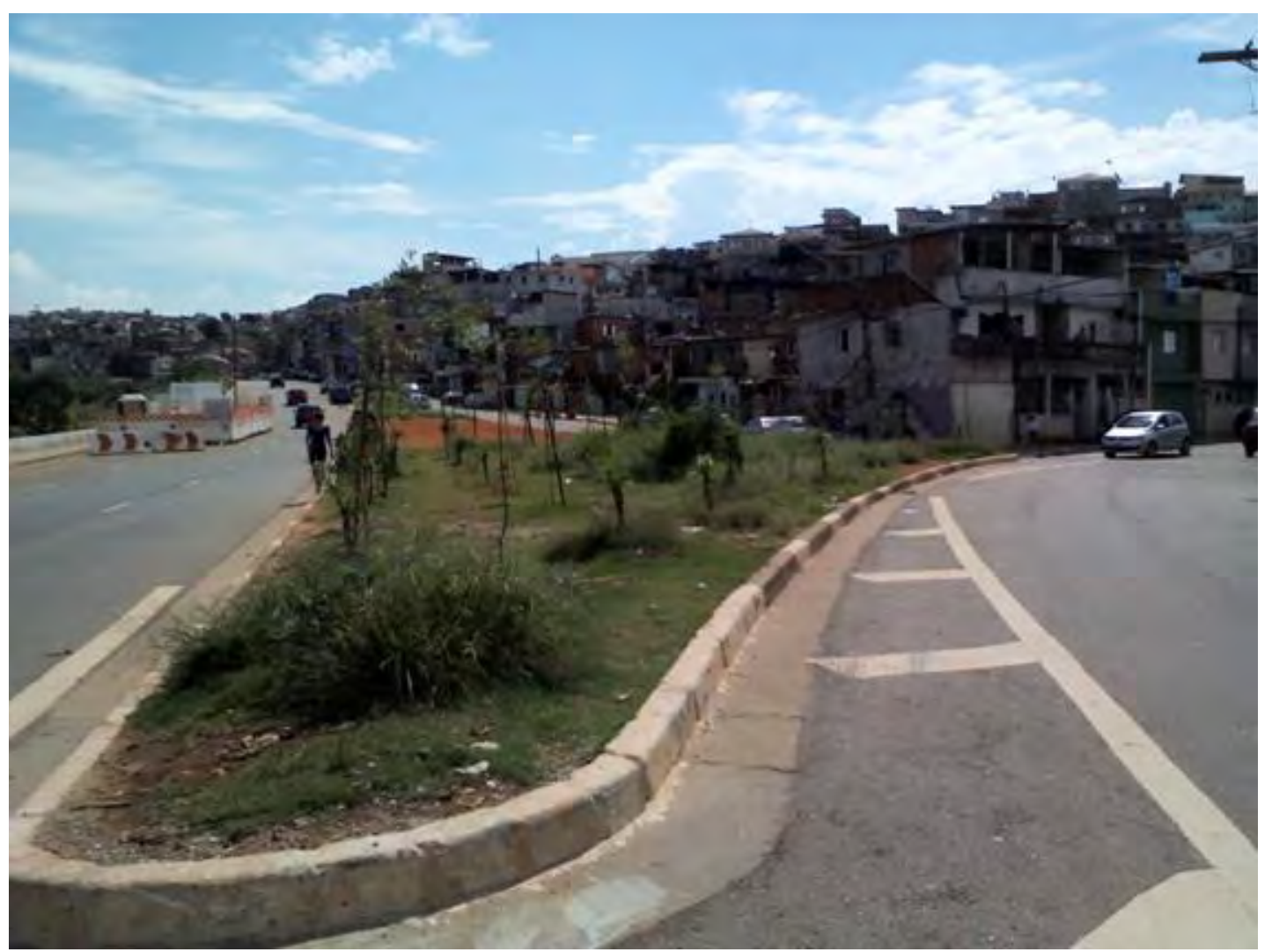

Figura 5: Construção clandestina e via pública pavimentada nas imediações da área destinada para o parque linear. Fonte: Imagem das autoras Isménia Andrade e Natacha Ferreira.

Proteção dos recursos naturais: uma vez que este parque linear se encontra inserido na Serra da Cantareira, cujo espólio vegetal e animal é extremamente rico e equilibrado, é mais fácil a recomposição de vegetação ciliar, de cobertura vegetal do solo (diminuição da erosão e de aluimentos de terra), contribuindo também para o desenvolvimento de ecossistemas ribeirinhos. Este parque atua como uma barreira de proteção da serra, dificultando a ocupação clandestina. 


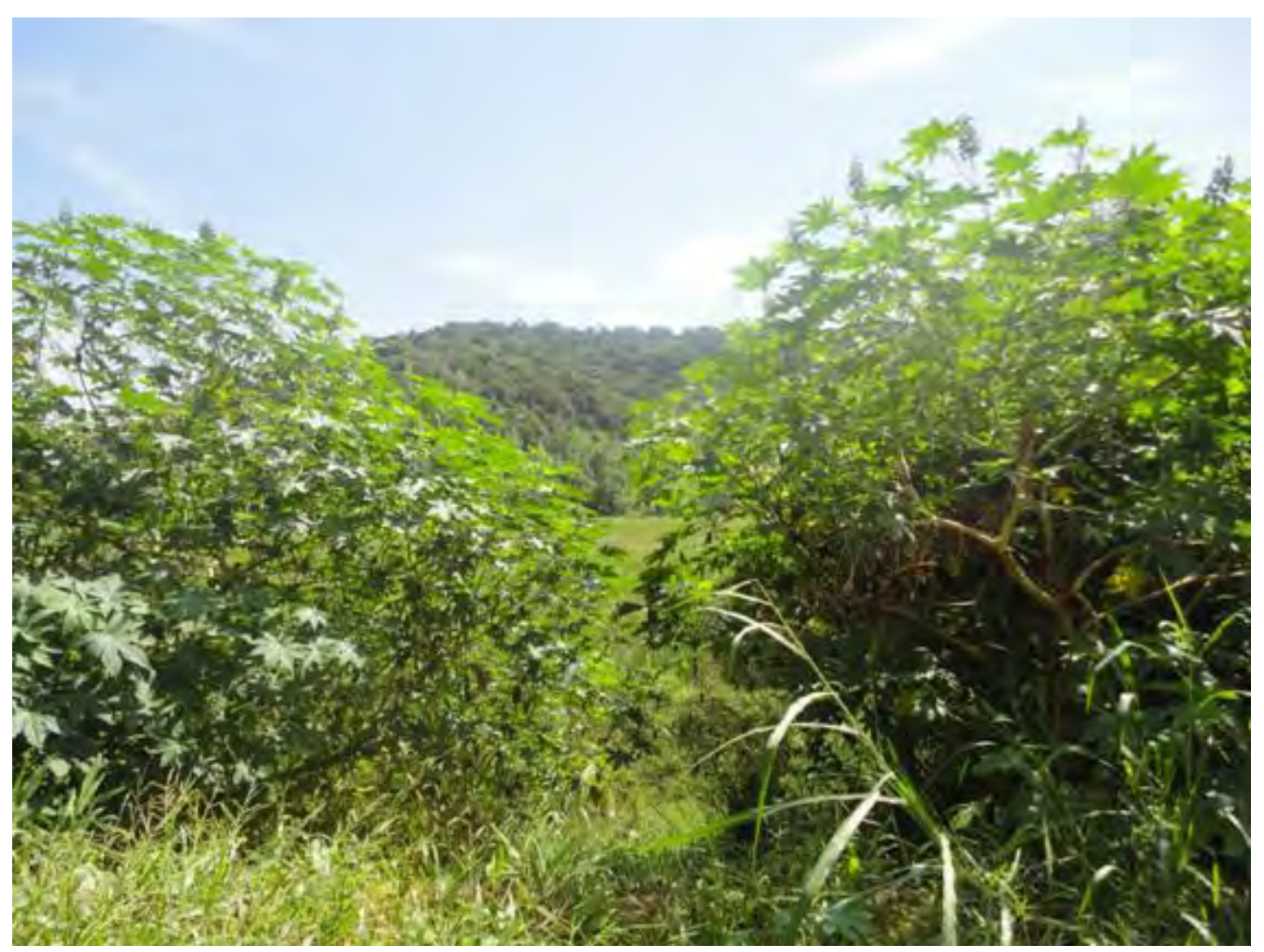

Figura 6: Vegetação existente na área da Serra da Cantareira destinada à construção do Parque Linear do Córrego do Bispo. Fonte: Imagem das autoras Isménia Andrade e Natacha Ferreira.

Proteção ambiental: parques Lineares são necessários como ponto de apoio no combate à poluição sonora, do ar e das águas, pois embora boa parte da poluição das águas chegue através da rede coletora de esgotos, os Parques Lineares ajudam de certa forma a impedir que objetos sejam jogados nos córregos e rios, além de servirem como argumento de conscientização ecológica da população (PORTAL GOVERNO DE SÃO PAULO, acesso em02/02/2011).

Saúde pública:em contexto de inexistência de saneamentos básicos, canalização de águas, enchentes frequentes, acumulação de lixos, existem riscos acrescidos de proliferação de doenças e epidemias. Os Parques Lineares atenuam estes efeitos ao aumentarem a capacidade de drenagem dos solos, ao fomentarem a biodiversidade e ao transformarem espaços desprezados em locais com valor estético e socialmente reconhecidos. 
$\diamond \quad$ Ação social e educação ambiental: a população que habita na área em estudo caracteriza-se por viver em condições desfavoráveis de extrema pobreza e de exclusão social e habitacional. Dado que os espaços livres são assumidos como locais prazerosos, que promovem momentos de descontração, atividades desportivas e fomentam as relações sociais, é indispensável para a região a finalização do projeto. Frischenbruder e Pellegrino (2006) ainda ressaltam que o Parque Linear insere no urbano as necessidades de recreação, educação ambiental e de coesão social, oferecendo uma diversidade de atividades a baixo custo para população.

Entre as diversas funções sociais que os Parques Lineares desempenham destacase:

$\diamond \quad$ Criação de espaços para recreio e lazer;

$\diamond \quad$ Criação de vias de circulação alternativa como ciclovias, pedonais, patins, skates, entre outras;

$\diamond \quad$ Contribuição para um melhor convívio social e para a manutenção e valorização da qualidade estética da paisagem;

$\diamond \quad$ Promoção de aulas práticas de ecologia e meio ambiente em localidades mais próximas de escolas e instituições de ensino.

A realização desta obra será uma mais-valia para todos. Com ela, a população local melhora a sua qualidade de vida e condições sanitárias de saúde pública. A região consegue maior estabilidade ambiental e usufrui de uma zona de lazer de rara beleza e riqueza paisagística. 


\section{REFERÊNCIAS BIBLIOGRÁFICAS}

AMORIM, J.M. O Estudo do Efeito da Urbanização e da Ocupação Urbana no Escoamento da Microbacia do Córrego Mogi em Uberlândia-MG. Uberlância. Dissertação de Mestrado da Faculdade de Engenharia Civil, Universidade Uberlândia, 2008.

BRAGA, Roberto; CARVALHO, Pompeu F. C. Recursos hídricos e planejamento urbano e regional. RioClaro: Laboratório de Planejamento Municipal - IGCE - UNESP, p. $113-127,2003$.

FRISCHENBRUDER, Marisa T Mamede ; PELLEGRINO, P. R. M. . Using greenways to reclaim nature in "Brazilian cities" Landscape and Urban Planning, v. 76, n. 1-4, p. 67-78, 2006.

SANCHEZ, L.E., Avaliação de Impacto Ambiental: Conceitos e Métodos. São Paulo: Oficina de Textos, 2006.SCALISE, W. Parques Urbanos, Evolução, Projeto, Funções e Usos. Marília. Revista da Faculdade de Engenharia, Arquitetura e Tecnologia de Marília-UNIMAR. 2002.

\section{Sites visitados}

http://atlasambiental.prefeitura.sp.gov.br/conteudo/cobertura vegetal/veg apres 02 . pdf

http://www.mananciais.org.br/2011/09/mananciais-diagnostico-e-politicas-habitacionais-pdf/

http://www.prefeitura.sp.gov.br/cidade/secretarias/planejamento/mapas e dados/

http://www.redaalc.com/sites/experienciasgestion/EG-SAOPAULOboas\%20praticas. pdf

www.saopaulo.sp.gov.br/spnoticias/lenoticia.php?id=203054

http://pt.scribd.com/doc/55639216/ARTIGO-ENEPEA-Potencialidade-dos-parqueslineares-na-recuperacao 